\title{
Aciditerrimonas ferrireducens gen. nov., sp. nov., an iron-reducing thermoacidophilic actinobacterium isolated from a solfataric field
}

\begin{abstract}
Correspondence
Takashi Itoh

ito@jcm.riken.jp
\end{abstract}

\author{
Takashi Itoh, ${ }^{1}$ Kaoru Yamanoi, ${ }^{1,2}$ Takuji Kudo, ${ }^{1}$ Moriya Ohkuma ${ }^{1}$ \\ and Tomonori Takashina ${ }^{3}$ \\ ${ }^{1}$ Japan Collection of Microorganisms, RIKEN BioResource Center, Wako, Saitama 351-0198, \\ Japan \\ ${ }^{2}$ Graduate School of Life Sciences, TOYO University, Oura, Gunma 374-0193, Japan \\ ${ }^{3}$ Faculty of Life Sciences, TOYO University, Oura, Gunma 374-0193, Japan
}

Solfataric fields, or geothermally heated areas associated with fumaroles emitting sulfurous gases containing $\mathrm{H}_{2} \mathrm{~S}$ and $\mathrm{SO}_{2}$, are located in various terrestrial regions near tectonically active zones. In such environments, extreme acidity, which is attributed to abiotic and biotic processes, including oxidation of $\mathrm{H}_{2} \mathrm{~S}$ to sulfur with atmospheric oxygen followed by oxidation of sulfur to sulfuric acid by sulfur-oxidizing bacteria and archaea, and elevated temperatures allow minerals to be partially or completely broken down (Brock, 1986; Johnson, 2007). Thus, solfataric fields harbour a variety of thermoacidophilic bacteria and archaea mediating geochemical processes. In an attempt to isolate various thermoacidophilic microorganisms from a solfataric field in Hakone, Japan (Itoh et al., 2007), a novel thermoacidophilic bacterial strain, designated IC- $180^{\mathrm{T}}$, which was phylogenetically affiliated

The GenBank/EMBL/DDBJ accession number for the $16 \mathrm{~S}$ rRNA gene sequence of IC- $180^{\top}$ is $\mathrm{AB} 517669$.

A supplementary figure is available with the online version of this paper. with acidophilic actinobacteria in the order Acidimicrobiales (Stackebrandt et al., 1997; Zhi et al., 2009), was isolated. At the time of writing, the order Acidimicrobiales comprises two families, Acidimicrobiaceae and Iamiaceae (Zhi et al., 2009; Kurahashi et al., 2009). The former family comprises three monospecific genera, Acidimicrobium (Clark \& Norris, 1996), Ferrimicrobium and Ferrithrix (Johnson et al., 2009), members of which are found in mineral-rich acidic environments such as mines and solfataric fields. In addition, a recently described genus with a name that has not yet been validly published, 'Acidithiomicrobium', is also affiliated with this family (Davis-Belmar \& Norris, 2009). In contrast, the latter family comprises the non-acidophilic species Iamia majanohamensis, which is associated with a marine animal (Kurahashi et al., 2009). In addition, the actinobacterium Ilumatobacter fluminis, isolated from estuary sediment (Matsumoto et al., 2009), may be included in the order Acidimicrobiales. The three genera of the family Acidimicrobiaceae are known to be mesophilic or moderately 
thermophilic, extremely acidophilic, and capable of oxidation and reduction of iron (Clark \& Norris, 1996; Bridge \& Johnson, 1998; Johnson et al., 2009). In this paper, the morphological, physiological, biochemical, chemotaxonomic and phylogenetic properties of strain IC- $180^{\mathrm{T}}$ were determined to reveal its taxonomic position. It is proposed that this isolate represents a novel species in a new genus in the order Acidimicrobiales.

Strain IC $-180^{\mathrm{T}}$ was isolated from a solfataric soil sample $\left(60{ }^{\circ} \mathrm{C}, \mathrm{pH} 1.4\right)$ collected at a solfataric field, Ohwaku-dani, Hakone, Japan, by applying the most-probable number method using Sulfolobus medium with $1.0 \mathrm{~g}$ yeast extract $\mathrm{l}^{-1}$ (Brock et al., 1972) at $\mathrm{pH} 2.5$ and $55^{\circ} \mathrm{C}$, as described previously (Itoh et al., 2007). It was the sole bacterial isolate from the sample, although several thermoacidophilic archaeal strains, which were identified or provisionally assigned by $16 \mathrm{~S}$ rRNA gene comparisons to the species Thermogymnomonas acidicola, Acidianus infernus, Acidianus brierleyi, Metallosphaera hakonensis and Picrophilus oshimae, were isolated from the same sample. The purity of the bacterial strain was confirmed by microscopic observation of cell morphology and repeated partial sequencing of the $16 \mathrm{~S}$ rRNA gene using several primers. Strain IC $-180^{\mathrm{T}}$ was routinely cultivated aerobically at $50{ }^{\circ} \mathrm{C}$ in modified Sulfolobus medium (the medium was amended with $1.0 \mathrm{~g}$ yeast extract $1^{-1}$, but $\mathrm{FeCl}_{3} \cdot 6 \mathrm{H}_{2} \mathrm{O}$ was omitted, $\mathrm{pH} 2.5$ ). Unless otherwise indicated, this medium was used as the basal medium for physiological and biochemical experiments. Acidimicrobium ferrooxidans JCM $15462^{\mathrm{T}}$ was used as a reference strain.

Cells of strain IC- $180^{\mathrm{T}}$ were Gram-positive, short rods $(0.5-0.6 \times 0.8-1.1 \mu \mathrm{m})$, occurring singly, in pairs or short chains during exponential to early stationary growth phase. They were motile, exhibiting tumbling motion. No endospores were observed. The platinum-palladium shadowed cells revealed peritrichous flagellation under a transmission electron microscope (as shown in Fig. 1).

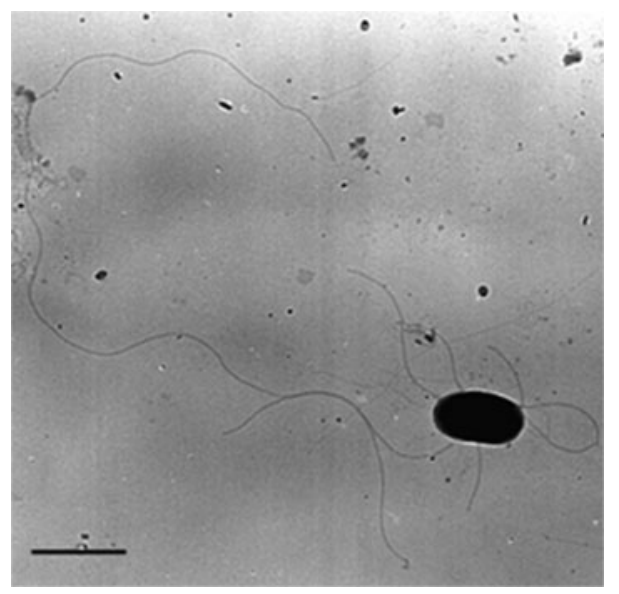

Fig. 1. Transmission electron micrograph of a cell with peritrichous flagella shadowed with platinum-palladium. Bar, $1 \mu \mathrm{m}$.
Colonies formed on an agar $(2 \%, \mathrm{w} / \mathrm{v})$ plate of modified Sulfolobus medium incubated aerobically for 1 week were tiny (less than $0.2 \mathrm{~mm}$ in diameter), convex and white to cream in colour.

Under air, strain IC- $180^{\mathrm{T}}$ grew between 35 and $58{ }^{\circ} \mathrm{C}$ and at $\mathrm{pH} 2.0-4.5$, with optimal growth at $50{ }^{\circ} \mathrm{C}$ and $\mathrm{pH} 3.0$; no growth was observed at 30 or $60^{\circ} \mathrm{C}$ or at $\mathrm{pH} 1.5$ or 5.0. The isolate grew heterotrophically using yeast extract. Alternatively, it utilized glucose, lactose, maltose, sucrose, xylose and glycogen as sole carbon and energy sources (at $0.5 \%, w / v)$. Fructose, galactose, mannose, ribose and starch supported weak growth, whereas arabinose, acetate, butyrate, citrate, formate, fumarate, lactate, propionate and succinate did not (carbohydrates at $0.5 \%$; organic acids at $0.2 \%)$. Addition of ferrous sulfate $(10 \mathrm{mM})$ or synthesized iron disulfide $\left(\mathrm{FeS}_{2}, 80 \mathrm{mM}\right)$ in the modified Sulfolobus medium did not affect growth and these substances were not oxidized.

Under anaerobic conditions (gas phase, $\mathrm{N}_{2}$ ), growth was observed in the modified Sulfolobus medium supplemented with $10 \mathrm{mM}$ ferric sulfate. The modified Sulfolobus medium without ferric sulfate did not support anaerobic growth, even if supplemented with sulfate, nitrate $(10 \mathrm{mM}$ each) or sulfur $(30 \mathrm{mM})$. Anaerobic growth in the presence of $10 \mathrm{mM}$ ferric sulfate was accompanied by the reduction of ferric iron [as indicated by the increase of ferrous iron according to the ferrozine assay as described by Phillips \& Lovley (1987); see Supplementary Fig. S1 available in IJSEM Online]. Ferric sulfate could be replaced with poorly crystalline Fe(III) oxide (Lovley \& Phillips, 1986), ferric chloride, ferric citrate or $\mathrm{Mn}(\mathrm{IV})$ oxide, but not with $\mathrm{Fe}$ (III). EDTA (all at $10 \mathrm{mM}$ ). On the other hand, yeast extract could be replaced with glucose, lactose, maltose, mannose, xylose, glycogen, citrate and pyruvate, but not with arabinose, fructose, galactose, ribose, sucrose, starch, acetate, butyrate, formate, fumarate, lactate, malate, propionate or succinate (carbohydrates at $0.5 \%, \mathrm{w} / \mathrm{v}$; organic acids at $0.2 \%, \mathrm{w} / \mathrm{v})$. In the presence of ferric iron, autotrophic growth occurred under a gas mixture of $\mathrm{H}_{2} /$ $\mathrm{CO}_{2}(4: 1, \mathrm{v} / \mathrm{v})$, but not in $\mathrm{N}_{2} / \mathrm{CO}_{2}(4: 1, \mathrm{v} / \mathrm{v})$, indicating that $\mathrm{H}_{2}$ acted as an electron donor.

Cells of strain IC- $180^{\mathrm{T}}$ contained meso-diaminopimelic acid as a diagnostic cell wall amino acid, according to the method of Hasegawa et al. (1983). The cellular fatty acid composition of strain IC- $180^{\mathrm{T}}$ was analysed by the MIDI system. It contained iso- $\mathrm{C}_{16: 0}(56.0 \%)$, anteiso- $\mathrm{C}_{17: 0}$ $(12.4 \%)$, iso- $\mathrm{C}_{18: 0}(11.4 \%)$, iso- $\mathrm{C}_{17: 0}(4.6 \%)$, anteiso$\mathrm{C}_{15: 0}(4.1 \%)$, iso- $\mathrm{C}_{17: 1} \omega 5 c(3.1 \%)$, iso- $\mathrm{C}_{16: 1} \mathrm{H}(1.4 \%)$, $\mathrm{C}_{17: 0}(1.1 \%)$, iso- $\mathrm{C}_{15: 0}(1.1 \%)$ and $\mathrm{C}_{16: 0}(1.1 \%)$. The menaquinone system and polar lipid composition were analysed as described by Minnikin et al. (1984). MK-9( $\left.\mathrm{H}_{8}\right)$ was a major component of the menaquinone system. The phospholipid lipid fraction contained diphosphatidylglycerol, phosphatidyl- $N$-methylethanolamine, an unknown ninhydrin-positive phosphoglycolipid, phosphatidylinositol and phosphatidylinositolmannoside. 
Total DNA was prepared from the isolate and DNA base composition was determined by the HPLC method as described by Tamaoka (1994). DNA G + C content was $74.1 \pm 0.3 \mathrm{~mol} \%$ (two determinations). The almost entire region of the $16 \mathrm{~S}$ rRNA gene was amplified and sequenced as described previously (Namwong et al., 2005). Of $1482 \mathrm{nt}$ positions determined, 1225 positions were compared for reconstruction of the phylogenetic tree after alignment with related strains and uncultured clones by the program CLUSTAL X (Thompson et al., 1997) followed by manual editing of the alignment. 16S rRNA gene sequence analysis revealed that strain $\mathrm{IC}-180^{\mathrm{T}}$ was a member of the order Acidimicrobiales. Currently, there are two families in this order: Acidimicrobiaceae, represented by the three species Acidimicrobium ferrooxidans, Ferrimicrobium acidiphilum and Ferrithrix thermotolerans (Clark \& Norris, 1996; Johnson et al., 2009); and family Iamiaceae, represented by the single species Iamia majanohamensis (Kurahashi et al., 2009). In the phylogenetic tree (Fig. 2), strain IC$180^{\mathrm{T}}$ formed a coherent cluster with two uncultured bacteria, one from an acidic geothermal site in Yellowstone National Park, USA (clone W2bXIIb31), and the other from a moderately thermophilic bioreactor operated in China (clone BS-B54) with similarities of $99.4-99.5 \%$. Other uncultured bacterial clones near this cluster (i.e. clones S5, BA84, SK299 and W2bXIIb31) were also detected from acidic and/or thermophilic habitats. This cluster was distantly related to the other two clusters corresponding to the two families of the order, i.e.
Acidimicrobiaceae and Iamiaceae. Sequence similarities between strain IC- $180^{\mathrm{T}}$ and the three known Acidimicrobiaceae species ranged from 93.3 to $92.0 \%$ and the similarity value between strain IC- $180^{\mathrm{T}}$ and Iamia majanohamensis $\mathrm{F} 12^{\mathrm{T}}$ was $91.5 \%$. The $16 \mathrm{~S}$ rRNA signature pattern was the same as that of the family Acidimicrobiaceae as indicated by Zhi et al. (2009), except for 952:1229 (U-A).

The present study reveals that strain IC- $180^{\mathrm{T}}$ is an acidophilic, moderately thermophilic actinobacterium capable of dissimilatory reduction of ferric iron with $\mathrm{H}_{2}$ or organic substances as electron donors for growth under anaerobic or autotrophic conditions. From the phylogenetic analysis, the strain can be placed in the order Acidimicrobiales; however, it is not affiliated with members of the two known families, Acidimicrobiaceae and Iamiaceae. The phenotypic properties of strain IC- $180^{\mathrm{T}}$ indicate that this isolate seems to be more related to species of the family Acidimicrobiaceae, which thrive in acidic, mineral-rich, moderately thermophilic habitats and are capable of dissimilatory iron metabolism. On the other hand, Iamia majanohamensis, the sole member of the family Iamiaceae, is a non-acidophile isolated from a sea cucumber. In addition, Ilumatobacter fluminis, whose family membership has not been clarified at present although it seems to be affiliated with the family Iamiaceae, inhabits marine sediments (Matsumoto et al., 2009). Iron-oxidation capability has been demonstrated for known species of the family Acidimicrobiaceae, as well as the two strains of 'Acidithiomicrobium', in pure or mixed

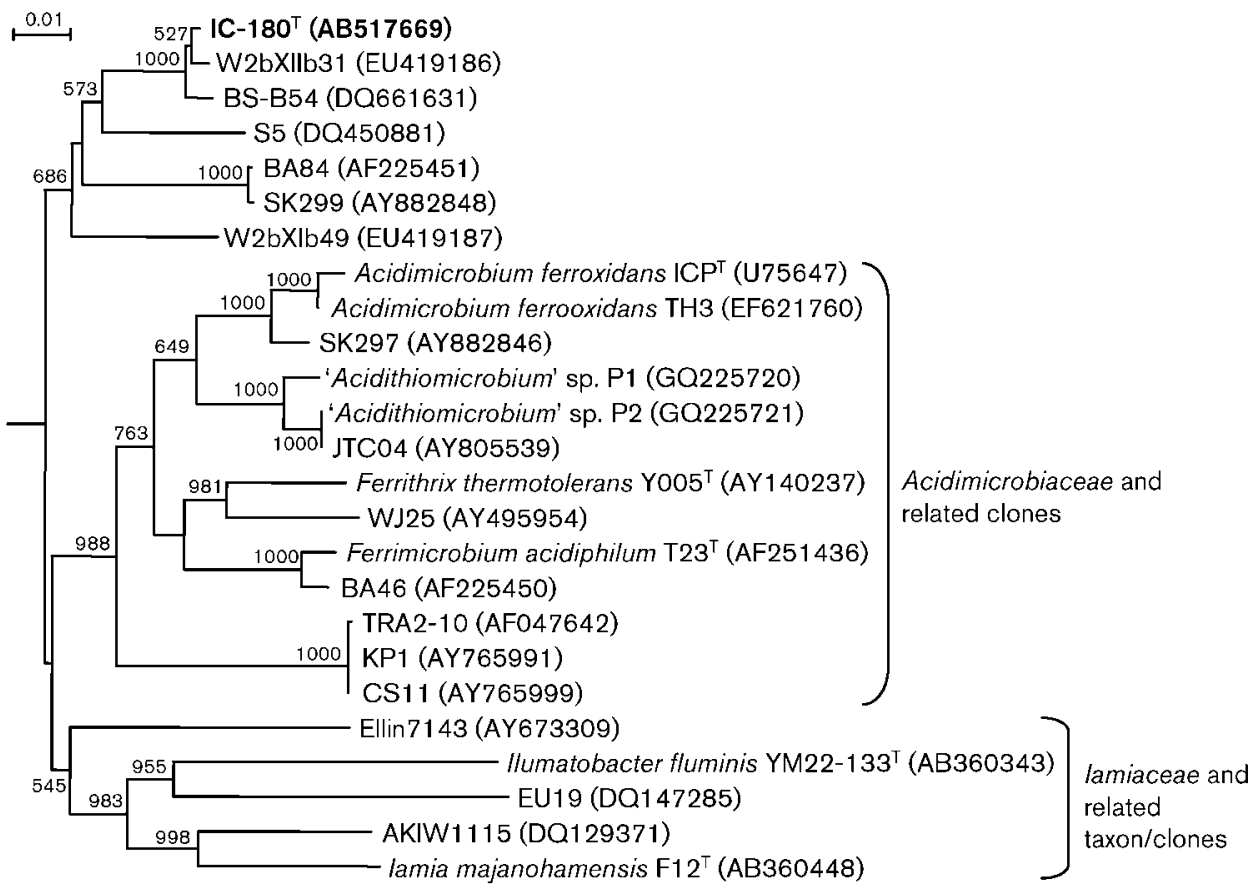

Fig. 2. Neighbour-joining phylogenetic tree based on $16 \mathrm{~S}$ rRNA gene sequences showing the position of strain $I C-180^{\top}$. Frankia sp. (L40622) was used as the outgroup. Numbers at nodes indicate bootstrap values based on 1000 resamplings (>500). Bar, 0.01 substitutions. 
culture (Brierley, 1978; Clark \& Norris, 1996; Johnson et al., 2003, 2009; Davis-Belmar \& Norris, 2009), but it was not observed for strain IC- $180^{\mathrm{T}}$. Ferrimicrobium acidiphilum and Ferrithrix thermotolerans are obligate heterotrophs, whereas Acidimicrobium ferrooxidans and strain IC- $180^{\mathrm{T}}$ are capable of growing under autotrophic conditions at moderately thermophilic temperatures (optimum growth at $45-50{ }^{\circ} \mathrm{C}$ ). Differential characteristics are summarized in Table 1. On the basis of the phenotypic, chemotaxonomic and phylogenetic properties, strain IC$180^{\mathrm{T}}$ represents a novel species in a new genus in the order Acidimicrobiales. Due to the distant lineage of strain IC$180^{\mathrm{T}}$ from the families Acidimicrobiaceae and Iamiaceae, this isolate may represent a new family; however, such a conclusion should not be drawn until other strains related to IC- $180^{\mathrm{T}}$ have been isolated and compared in detail with members of all genera of the order Acidimicrobiales. Here, the name Aciditerrimonas ferrireducens gen. nov., sp. nov. is proposed to accommodate strain IC- $180^{\mathrm{T}}$; the type strain is IC $-180^{\mathrm{T}}\left(=\mathrm{JCM} 15389^{\mathrm{T}}=\right.$ DSM $\left.45281^{\mathrm{T}}\right)$.

\section{Description of Aciditerrimonas gen. nov.}

Aciditerrimonas (A.ci.di.ter.ri.mo' nas. L. neut. n. acidum an acid; L. n. terra soil; L. fem. n. monas a unit, monad; N.L. fem. $\mathrm{n}$. Aciditerrimonas acidic soil monad).

Cells are short rods, $0.5-0.6 \times 0.8-1.1 \mu \mathrm{m}$, motile with peritrichous flagella. Gram-positive. Do not form spores. Thermoacidophilic, growing optimally at $50{ }^{\circ} \mathrm{C}$ and $\mathrm{pH} 3.0$. Facultatively anaerobic and autotrophic. Capable of reducing ferric iron. The peptidoglycan contains meso-diaminopimelic acid. The major cellular fatty acids are iso- $\mathrm{C}_{16: 0}$, anteiso$\mathrm{C}_{17: 0}$ and iso- $\mathrm{C}_{18: 0}$. The major quinone component is MK- $9\left(\mathrm{H}_{8}\right)$. The phospholipid composition includes phosphatidyl- $\mathrm{N}$-methylethanolamine and an unknown ninhydrin-positive phosphoglycolipid. Phylogenetically affiliated in the order Acidimicrobiales according to 16S rRNA gene sequence comparisons. The $16 \mathrm{~S}$ rRNA signature pattern is the same as that of the family Acidimicrobiaceae as indicated by Zhi et al. (2009), except for 952:1229 (U-A). The type species is Aciditerrimonas ferrireducens.

\section{Description of Aciditerrimonas ferrireducens sp. nov.}

Aciditerrimonas ferrireducens (fer.ri.re.du'cens. L. n. ferrum iron; L. part. adj. reducens bringing back, leading back; N.L. part. adj. ferrireducens iron-reducing).

Morphological, cultural properties, chemotaxonomic and phylogenetic features are as described for the genus. Grows at $35-58{ }^{\circ} \mathrm{C}$ (optimally at $50{ }^{\circ} \mathrm{C}$ ) and $\mathrm{pH} 2.0-4.5$ (optimally at $\mathrm{pH} 3.0$ ). Grows aerobically, or anaerobically in the presence of ferric iron. Heterotrophic growth occurs using yeast extract, glucose, lactose, mannose and xylose as carbon and energy sources. Autotrophic growth occurs by reducing ferric iron with hydrogen under anaerobic conditions. Does not oxidize ferrous iron.

The type strain is IC $-180^{\mathrm{T}}\left(=\mathrm{JCM} 15389^{\mathrm{T}}=\mathrm{DSM} 45281^{\mathrm{T}}\right)$, which was isolated from solfataric soil at Ohwaku-dani, Hakone, Japan. The DNA G $+\mathrm{C}$ content of the type strain is $74 \mathrm{~mol} \%$.

Table 1. Major characteristics that distinguish strain IC-180 ${ }^{\top}$ from known genera of the order Acidimicrobiales

Taxa: 1, strain IC- $180^{\mathrm{T}}$ (data from this study); 2, Acidimicrobium (data from Clark \& Norris, 1996, except where marked); 3, Ferrimicrobium (data from Johnson et al., 2009); 4, Ferrithrix (data from Johnson et al., 2009); 5, Iamia (data from Kurahashi et al., 2009); 6, Ilumatobacter (data from Matsumoto et al., 2009). ND, No data available.

\begin{tabular}{|c|c|c|c|c|c|c|}
\hline Characteristic & 1 & 2 & 3 & 4 & 5 & 6 \\
\hline Cell shape & Short rod & Rod & Rod & Filament & Rod & Rod \\
\hline Gram reaction & + & + & - & - & + & + \\
\hline Motility & + & + & + & - & - & - \\
\hline Growth temperature $\left({ }^{\circ} \mathrm{C}\right)^{*}$ & 50 & $45-50$ & 35 & 43 & $28-30$ & $26-31$ \\
\hline Growth $\mathrm{pH}^{*}$ & 3.0 & 2.0 & 2.0 & 1.8 & 7.0 & $7-11$ \\
\hline Autotrophic growth & + & + & - & - & ND & ND \\
\hline Oxidation of ferrous iron & - & + & + & + & ND & ND \\
\hline Major fatty acids $\dagger$ & $\begin{array}{c}\mathrm{i}-\mathrm{C}_{16: 0}, \text { ai- } \mathrm{C}_{17: 0} \\
\mathrm{i}-\mathrm{C}_{18: 0}\end{array}$ & $\begin{array}{l}\mathrm{i}-\mathrm{C}_{16: 0}, \\
\text { ai- } \mathrm{C}_{17: 0}\end{array}$ & $\mathrm{i}-\mathrm{C}_{16: 0}$, ai- $\mathrm{C}_{15: 0}$ & $\mathrm{i}-\mathrm{C}_{16: 0}$ & $\mathrm{C}_{17: 0}, \mathrm{C}_{17: 1} \omega 8 c$ & $\begin{array}{c}\mathrm{C}_{16: 0}, \mathrm{C}_{17: 1} \omega 9 c, \\
\mathrm{i}-\mathrm{C}_{17: 0}\end{array}$ \\
\hline Major menaquinone & MK-9 $\left(\mathrm{H}_{8}\right)$ & $\mathrm{MK}-9\left(\mathrm{H}_{8}\right) \ddagger$ & MK- $8\left(\mathrm{H}_{10}\right)$ & ND & MK-9 $\left(\mathrm{H}_{6}\right)$ & MK-9 $\left(\mathrm{H}_{8}\right)$ \\
\hline DNA G $+\mathrm{C}$ content $(\mathrm{mol} \%)$ & 74 & $67-69$ & 55 & 50 & 74 & 68 \\
\hline $\begin{array}{l}\text { Isolated from geothermal/mine } \\
\text { habitat }\end{array}$ & + & + & + & + & - & - \\
\hline
\end{tabular}

${ }^{\star}$ Optimum values are given, except for the genus Ilumatobacter, where the range is shown.

$\dagger$ Components present at more than $5 \%$ total fatty acids are given, except for the genera Iamia and Ilumatobacter, where components more than $10 \%$ are shown.

$\ddagger$ Data from this study. 


\section{Acknowledgements}

This work was supported, in part, by Grants-in-Aid for Scientific Research from the Japan Society for the Promotion of Science (no. 13660338).

\section{References}

Bridge, T. A. M. \& Johnson, D. B. (1998). Reduction of soluble iron and reductive dissolution of ferric iron-containing minerals by moderately thermophilic iron-oxidizing bacteria. Appl Environ Microbiol 64, 2181-2186.

Brierley, J. A. (1978). Thermophilic iron-oxidizing bacteria found in copper leaching dumps. Appl Environ Microbiol 36, 523-525.

Brock, T. D. (1986). Introduction: an overview of the thermophiles. In Thermophiles: General, Molecular and Applied Microbiology, pp. 1-16. Edited by T. D. Brock. New York: Wiley.

Brock, T. D., Brock, K. M., Belly, R. T. \& Weiss, R. L. (1972). Sulfolobus: a new genus of sulfur-oxidizing bacteria living at low $\mathrm{pH}$ and high temperature. Arch Mikrobiol 84, 54-68.

Clark, D. A. \& Norris, P. R. (1996). Acidimicrobium ferrooxidans gen. nov., sp. nov.: mixed-culture ferrous iron oxidation with Sulfobacillus species. Microbiology 142, 785-790.

Davis-Belmar, C. S. \& Norris, P. R. (2009). Ferrous iron and pyrite oxidation by "Acidithiomicrobium" species. Adv Matr Res 71-73, 271274.

Hasegawa, T., Takizawa, M. \& Tanida, S. (1983). A rapid analysis for chemical grouping of aerobic actinomycetes. J Gen Appl Microbiol 29 319-322.

Itoh, T., Yoshikawa, N. \& Takashina, T. (2007). Thermogymnomonas acidicola gen. nov., sp. nov., a novel thermoacidophilic, cell wall-less archaeon in the order Thermoplasmatales, isolated from a solfataric soil in Hakone, Japan. Int J Syst Evol Microbiol 57, 2557-2561.

Johnson, D. B. (2007). Physiology and ecology of acidophilic microorganisms. In Physiology and Biochemistry of Extremophiles, pp. 257-270. Edited by C. Gerday \& N. Glansdorff. Washington, DC: American Society for Microbiology.

Johnson, D. B., Okibe, N. \& Roberto, F. F. (2003). Novel thermoacidophilic bacteria isolated from geothermal sites in Yellowstone National Park: physiological and phylogenetic characteristics. Arch Microbiol 180, 60-68.
Johnson, D. B., Bacelar-Nicolau, P., Okibe, N., Thomas, A. \& Hallberg, K. B. (2009). Ferrimicrobium acidiphilum gen. nov., sp. nov. and Ferrithrix thermotolerans gen. nov., sp. nov.: heterotrophic, ironoxidizing, extremely acidophilic actinobacteria. Int J Syst Evol Microbiol 59, 1082-1089.

Kurahashi, M., Fukunaga, Y., Sakiyama, Y., Harayama, S. \& Yokota, A. (2009). Iamia majanohamensis gen. nov., sp. nov., an actinobacterium isolated from sea cucumber Holothuria edulis, and proposal of Iamiaceae fam. nov. Int J Syst Evol Microbiol 59, 869-873.

Lovley, D. R. \& Phillips, E. J. P. (1986). Availability of ferric iron for microbial reduction in bottom sediments of the freshwater tidal Potomac River. Appl Environ Microbiol 52, 751-757.

Matsumoto, A., Kasai, H., Matsuo, Y., Ōmura, S., Shizuri, Y. \& Takahashi, Y. (2009). Ilumatobacter fluminis gen. nov., sp. nov., a novel actinobacterium isolated from the sediment of an estuary. J Gen Appl Microbiol 55, 201-205.

Minnikin, D. E., O’Donnell, A. G., Goodfellow, M., Alderson, G., Athalye, M., Schaal, A. \& Parlett, J. H. (1984). An integrated procedure for the extraction of bacterial isoprenoid quinones and polar lipids. J Microbiol Methods 2, 233-241.

Namwong, S., Tanasupawat, S., Smitinont, T., Visessanguan, W., Kudo, T. \& Itoh, T. (2005). Isolation of Lentibacillus salicampi strains and Lentibacillus juripiscarius sp. nov. from fish sauce in Thailand. Int J Syst Evol Microbiol 55, 315-320.

Phillips, E. J. P. \& Lovley, D. R. (1987). Determination of Fe(III) and $\mathrm{Fe}(\mathrm{II})$ in oxalate extracts of sediment. Soil Sci Soc Am J 51, 938-941.

Stackebrandt, E., Rainey, F. A. \& Ward-Rainey, N. L. (1997). Proposal for a new hierarchic classification system, Actinobacteria classis nov. Int J Syst Bacteriol 47, 479-491.

Tamaoka, J. (1994). Determination of DNA base composition. In Chemical Methods in Prokaryotic Systematics, pp. 463-470. Edited by M. Goodfellow \& A. G. O’Donnell. Chichester: Wiley.

Thompson, J. D., Gibson, T. J., Plewniak, F., Jeanmougin, F. \& Higgins, D. G. (1997). The CLUSTAL_X windows interface: flexible strategies for multiple sequence alignment aided by quality analysis tools. Nucleic Acids Res 25, 4876-4882.

Zhi, X.-Y., Li, W.-J. \& Stackebrandt, E. (2009). An update of the structure and $16 \mathrm{~S}$ rRNA gene sequence-based definition of higher ranks of the class Actinobacteria, with the proposal of two new suborders and four new families and emended descriptions of the existing higher taxa. Int J Syst Evol Microbiol 59, 589-608. 